http://ejournal.undip.ac.id/index.php/kapal

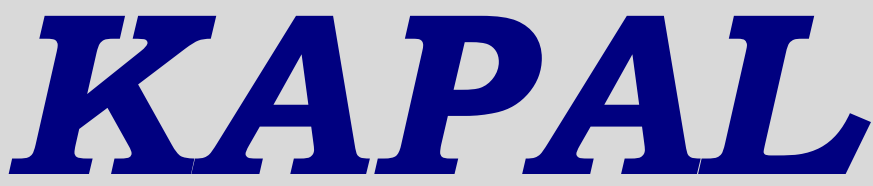

\title{
Simulasi Numerik Large-Deformation Surface Wave Dengan Smoothed Particle Hydrodynamics
}

\author{
Andi Trimulyono $^{1 *}$, Ardhana Wicaksono ${ }^{2)}$ \\ ${ }^{1)}$ Graduate School of Maritime Sciences, Kobe University, Kobe 658-0022, Japan \\ ${ }^{2)}$ Department of Naval Architecture and Ocean Engineering, Graduate School of Engineering, Osaka \\ University, Osaka 565-087, Japan
}

\begin{abstract}
Abstrak
Studi mengenai gelombang permukaan (surface wave) telah banyak dilakukan baik secara eksperimen, teoritis maupun komputasi. Perkembangan teknologi komputer membuat komputasi dinamika fluida komputasi menjadi lebih cepat dan efisien salah teknologi untuk mempercepat komputasi general purpose of computing Graphics processor units(GPGPU). Pada artikel ini komputasi numerik large-deformation surface wave dilakukan dengan Graphics processor units (GPUs). Simulasi numerik large-deformation surface wave menggunakan SPH dalam 2D dan 3D. Untuk mendapatkan efek dari perubahan kedalaman secara simultan digunakan box pada numerical wave tank (NWT) fenomena ini dikenal sebagai "bank effect". Tujuan dari studi ini adalah untuk mereproduksi fenomena fisik dari pemodelan gelombang reguler maupun gelombang nonlinear dengan menggunakan obstacle box untuk mereproduksi fenomena large-deformation surface wave. Manfaat dari studi ini adalah fenomena large-deformation surface wave dapat direproduksi dengan SPH serta aplikasi SPH untuk permasalahan yang lebih kompleks dalam bidang teknik kelautan. Hasil dari studi ini menunjukan bahwa simulasi numerik SPH untuk large-deformation surface wave $2 D$ dan $3 D$ dapat direproduksi oleh SPH. SPH memiliki akurasi yang cukup tinggi baik untuk elevasi gelombang reguler maupun nonlinear.
\end{abstract}

Copyright (C) 2018, KAPAL, 1829-8370 (p), 2301-9069(e)

Kata Kunci : large-deformation surface wave, GPGPU, SPH, numerical wave tank

\section{PENDAHULAN}

Studi mengenai gelombang permukaan telah banyak dilakukan oleh peneliti baik menggunakan eksperimen, teoritis dan komputasi menggunakan komputer. Perkembangan teknologi komputer yang pesat membuat komputasi dinamika fluida komputasi $(C F D)$ menjadi lebih cepat dan efisien. Salah satu teknologi komputasi yaitu penggunaan Graphics processor units (GPUs) untuk komputasi numerik atau biasa disebut general purpose of computing graphics processor units(GPGPU) [1].

GPUs yang awalnya dikembangkan untuk industri video games merupakan salah satu alat

*) Penulis Korespondensi :

Email : anditrimulyono@gmail.com yang murah dan efisien untuk mempercepat komputasi dinamika fluida komputasi[1]. Salah satu aplikasi dari dinamika fluida komputasi adalah pemodelan gelombang pada numerical wave tank (NWT). Karena permasalahan gelombang berkaitan erat dengan aliran freesurface dan large-deformation maka smoothed particle hydrodynamics (SPH) sangat tepat untuk digunakan.

SPH merupakan salah satu metode dinamika fluida komputasi non-grid dan termasuk dalam metode Lagrangian. SPH pertama kali digunakan untuk permasalahan astrofisika [2], namun dalam perkembanganya Monaghan mengembangkannya untuk permasalahan aliran free-surface [3] dimana 
contoh permasalahan ini adalah dam break dan simulasi gelombang.

Simulasi gelombang pada NWT telah banyak dilakukan baik dengan metode grid amupun nongrid. Salah satu keuntungan metode non-grid adalah tidak perlunya algoritma khusus untuk mendeteksi free-surface, tidak perlunya pembuatan grid structure yang menyita waktu dan karena tidaknya adanya grid membuat metode ini cocok untuk permasalahan free-surface flow di bidang teknik kelautan dan pantai.

Aplikasi SPH pada bidang teknik pantai diantaranya menghitung gaya hidrodinamik untuk interaksi fluida dan struktur pada bangunan pesisir pantai $[4,5]$. Altomare et al. menggunakan SPH untuk memvalidasi gelombang reguler dan irreguler dengan gelombang Stokes order dua [6]. Pemodelan gelombang menggunakan SPH juga memiliki akurasi yang cukup tinggi dengan menggunakan NWT yang cukup besar [7].

Studi ini mengkaji mengenai pengaruh kedalaman air terhadap gelombang permukaan atau sering disebut juga "bank effect". Dimana pergantian kedalaman air terjadi secara simultan dengan mengunakan box pada 2D dan 3D NWT. Simulasi gelombang permukaan dilakukan dengan menggunakan open source SPH-solver DualSPHysics versi 4.0 [8]. Penelitian terdahulu menunjukkan SPH memiliki akurasi yang cukup tinggi untuk analisa 2D "bank effect" dengan menggunakan NWT yang besar [9].

Studi ini bertujuan untuk mereproduksi simulasi numerik large-deformation surface wave atau dikenal juga "bank effects" dengan SPH baik dengan simulasi 2D maupun 3D dengan dimensi NWT berukuran sedang. Adapun manfaaat dari studi ini adalah fenomena large-deformation surface wave dapat direproduksi dengan SPH serta peluang penggunaan SPH untuk permasalahan yang lebih kompleks dalam bidang teknik kelautan maupun teknik pada umumnya.

\section{METODE}

\subsection{Metode SPH}

SPH merupakan salah satu metode dinamika fluida komputasi yang berbasis Lagrangian dan non-grid yang dikembangkan pertama kali oleh Monaghan untuk masalah astrofisika [2]. Namun dalam perkembangannya metode ini dikembangkan untuk aliran-aliran free-surface [3]. Untuk lebih detail mengenai basis theory dari SPH dapat merujuk ke Liu et al. [10]. Dalam SPH domain permasalahan di diskritasi dengan titik/partikel. Tiap partikel membawa properti seperti massa, kecepatan atau posisi masing- masing. SPH menggunakan metode interpolasi untuk menghitung kuantitas properti fisik suatu titik/partikel maka metode ini bisa disebut juga interpolan method. Bila suatu suatu fungsi $F(\boldsymbol{r})$ dalam domain $\Omega$ dapat didekati dengan pendekatan integral seperti pesamaan (1) dimana $W$ adalah kernel function dan $\boldsymbol{r}$ adalah vector posisi.

$$
F(\boldsymbol{r})=\int_{\Omega} F\left(\boldsymbol{r}^{\prime}\right) W\left(\boldsymbol{r}-\boldsymbol{r}^{\prime}, h\right) d \boldsymbol{r}^{\prime}
$$

Persamaan (1) jika dalam bentuk diskrit dapat diubah dengan mengubah bentuk integral dengan sebuah penjumlahan partikel yang terdapat dalam suatu kernel function pada partikel a. Persamaan (1) berubah menjadi persamaan(2) dimana volume dari suatu partikel $b$ adalah $m_{b} / \rho_{b}$.

$$
F\left(\boldsymbol{r}_{\boldsymbol{a}}\right) \approx \sum_{b} F\left(\boldsymbol{r}_{\boldsymbol{b}}\right) W\left(\boldsymbol{r}_{\boldsymbol{a}}-\boldsymbol{r}_{\boldsymbol{b}}, h\right) \frac{m_{b}}{\rho_{b}}
$$

Pada simulasi SPH ini kita menggunakan Wendland kernel function [11]. Persamaan (3) merupakan bentuk fungsi dari Wendland kernel function dimana $\alpha_{D}$ sama dengan $7 / 4 \pi h^{2}$ dalam 2D dan 21/164 $\pi h^{3}$ pada 3D. $q$ merupakan jarak tidak berdimensi antar partikel $a$ dan $b$ yang didefinisikan $r / h$ dengan $h$ adalah smoothing length.

$$
W(q)=\alpha_{D}\left(1-\frac{q}{2}\right)^{4}(2 q+1) \quad 0 \leq q \leq 2
$$

Persamaan (4) merupakan bentuk persamaan momentum dimana untuk efek dari disipasi menggunakan artificial viscosity $\left(\Pi_{a b}\right)$ yang dikembangkan oleh Monaghan [12]. Dimana $\mu_{a b}=h \boldsymbol{v}_{a b} \cdot \frac{\boldsymbol{r}_{a b}}{\left(\boldsymbol{r}_{a b}^{2}+\eta^{2}\right)} ; \boldsymbol{r}_{a b}=\boldsymbol{r}_{a}-\boldsymbol{r}_{b} ; \boldsymbol{v}_{a b}=$ $\boldsymbol{v}_{a}-\boldsymbol{v}_{b}$ dengan $\boldsymbol{v}$ dan $\boldsymbol{r}$ adalah vector kecepatan dan posisi dan $\eta^{2}=0.01 h^{2}, \overline{c_{a b}}=0.5\left(c_{a}+c_{b}\right)$ adalah rata-rata kecepatan suara antar partikel.

$$
\begin{gathered}
\frac{\boldsymbol{d} v_{a}}{d t}=-\sum_{b} m_{b}\left(\frac{P_{a+P_{b}}}{\rho_{a} \cdot \rho_{b}}+\Pi_{a b}\right) \nabla_{a} W_{a b}+\mathrm{g} \\
\Pi_{a b}= \begin{cases}\frac{-\alpha \overline{c_{a b}} \mu_{a b}}{\overline{\rho_{a b}}} & \boldsymbol{v}_{a b} \cdot \boldsymbol{r}_{a b}<0 \\
0 & \boldsymbol{v}_{a b} \cdot \boldsymbol{r}_{a b}>0\end{cases}
\end{gathered}
$$

Persamaan (5) merupakan persamaan kontinuitas SPH tanpa delta-SPH. Persamaan (6) merupakan persamaan kontinuitas dengan deltaSPH berdasarkan bentuk dari Molteni and Colagrossi[13].

$$
\frac{d \rho_{a}}{d t}=\sum_{b} m_{b}\left(\boldsymbol{v}_{a}-\boldsymbol{v}_{b}\right) \nabla_{a} W_{a b}
$$


$\frac{d \rho_{a}}{d t}=\sum_{b} m_{b} \boldsymbol{v}_{a b} \cdot \nabla_{a} W_{a b}+$

$2 \delta h c_{0} \sum_{b}\left(\rho_{b-} \rho_{a}\right) \frac{\boldsymbol{r}_{a b} \cdot \nabla_{a} W_{a b}}{r_{a b}^{2}} \frac{m_{b}}{\rho_{b}}$

Karena DualSPHysics berdasarkan weakly compressible SPH (WCSPH), diperlukan persamaan equation of state untuk menghitung tekanan berdasarkan densitas. Persamaan (7) merupakan equatian of state dari $\mathrm{SPH}$ berdasarkan Tait's equation. Dimana $b=\frac{c_{0}^{2} \rho_{0}}{\gamma}, c_{0}$ $=c\left(\rho_{0}\right)=\left.\sqrt{\frac{\partial P}{\partial \rho}}\right|_{\rho 0}$ dengan $c_{o}, \rho_{0}$ and $\gamma$ adalah kecepatan suara, densitas acuan, dan konstanta polytrophic .

$$
P=b\left[\left(\frac{\rho}{\rho_{0}}\right)^{\gamma}-1\right]
$$

\subsection{Permodelan Numerik di NWT}

Sebelum melakukan simulasi numerik dengan SPH, beberapa eksperimen telah dilakukan di towing tank Kobe University. Towing tank memiliki panjang $60,0 \mathrm{~m}$, lebar 6,0 $\mathrm{m}$ dan kedalaman air yang biasa diatur hingga maksimum 1,5 m. Data eksperimen pada artikel ini merupakan hasil dari penelitian sebelumnya[9]. Wave probe diletakkan $6,0 \mathrm{~m}$ didepan pembangkit gelombang. Pembangkit gelombang menggunakan periode $1,15 \mathrm{~s}$ dan kedalaman air $0,4 \mathrm{~m}$.

Untuk mendapatkan efek pergantian kedalaman air secara simultan diletakan box di NWT dengan jarak 6,0 m didepan pembangkit gelombang. Dimensi box dengan tinggi $0,25 \mathrm{~m}$, lebar 0,3 dan panjang 0,5 $\mathrm{m}$. Wave probe diletakan ditengah box yang jaraknya 6,0 dari pembangkit gelombang, untuk lebih jelasnya lihat Gambar 1.

Time histories dari pembangkit gelombang ditunjukkan pada Gambar 2. Grafik ini merupakan hasil dari eksperimen untuk gerakan wave-making board / piston pada wavemaker. Dimana gerakan pembangkit gelombang didapatkan dengan menggunakan sensor laser yang diletakan didepan pembangkit gelombang. Untuk lebih detail mengenai eksperimen yang telah dilakukan dapat dilihat pada referensi [9].

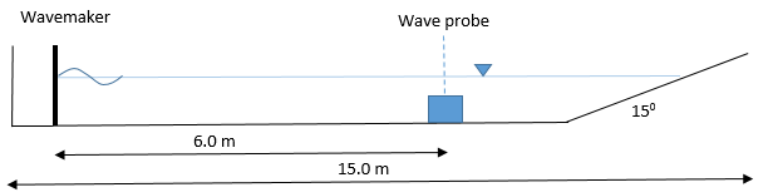

Gambar 1. Sketsa pemodelan numerik 2D and 3D di NWT.

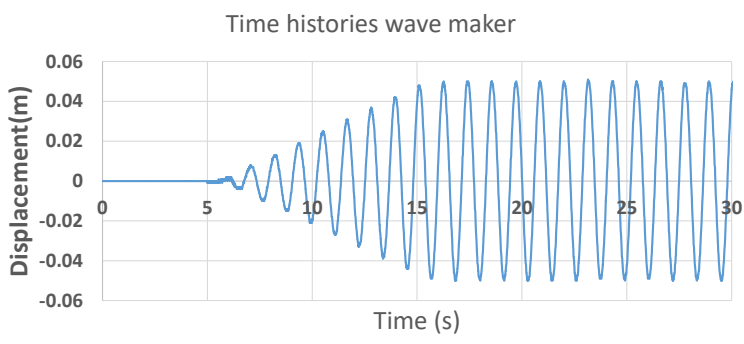

Gambar 2. Time histories gerakan pembangkit gelombang di NWT.

Pada pemodelan numerik gelombang dengan SPH, piston pembangkit gelombang diberikan waktu $5 \mathrm{~s}$ untuk kondisi statik kemudian piston bergerak sesuai dengan time histories sesuai dari input motion yang diberikan. Tabel 1 . Menunjukkan parameter yang di gunakan di DualSPHysics. Jarak partikel adalah $4.5 \mathrm{~mm}$ sehingga total partikel untuk 2D adalah 151.014 dan untuk 3D adalah 11.779.752. Simulasi SPH dilakukan menggunakan GPU GeForce GTX 10808 GB DDR5 total simulasi untuk 30 s adalah $11.3 \mathrm{jam}$.

Tabel 1. Parameter setup di DualSPHysics

\begin{tabular}{lc}
\hline \multicolumn{1}{c}{ Jenis Parameter } & Nilai \\
\hline Kernel Function & Wendland \\
Time step algorithm & Sympletic \\
Artificial viscosity coeff. $\alpha$ & 0,01 \\
Coefsound & 20,0 \\
Particle spacing $(\mathrm{mm})$ & 4,5 \\
Coefh & 1,2 \\
CFL number & 0,3 \\
Delta-SPH & 0,1 \\
Simulation time & 30,0 \\
\hline
\end{tabular}

\section{HASIL DAN PEMBAHASAN}

Hasil simulasi numerik SPH untuk tanpa adanya box ditunjukkan pada Gambar 3. Berdasarkan hasil simulasi SPH dengan eksperimen untuk wave probe $6,0 \mathrm{~m}$ menunjukkan SPH memiki akurasi yang tinggi untuk elevasi gelombang reguler tanpa adanya box. Simulasi ini merupakan simulasi SPH 2D dan simulasi 3D dilakukan setelah simulasi 2D tervalidasi dengan eksperimen.

Gambar 3. memperlihatkan bahwa SPH memiliki akurasi yang cukup tinggi. Ini diperlihatkan kecepatan gelombang antara SPH dengan eksperimen memiliki hasil yang sama, dimana tidak terjadinya beda phase pada grafik elevasi gelombang. Gelombang pertama yang sampai pada wave probe juga memiliki hasil yang sama dengan eksperimen. Elevasi gelombang antara SPH dengan eksperimen pun memiliki akurasi yang cukup tinggi berdasarkan Gambar 3 . 


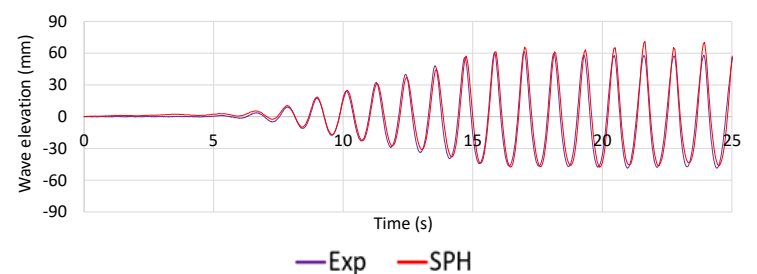

Gambar 3. Perbandingan hasil tinggi elevasi gelombang antara SPH dan eksperimen.

Gambar 4. memperlihatkan hasil simulasi SPH untuk large-deformation surface wave dengan menggunakan box. Dengan menggunakan periode $1,15 \mathrm{~s}$ maka panjang gelombang adalah 2,0 m sehingga diperlukan 3 gelombang untuk mencapai wave probe.

Gambar 4. menunjukkan gelombang sebelum melewati box berbentuk reguler namun saat gelombang mulai melewati box berubah menjadi nonlinear. Ini dikarenakan saat gelombang melewati box gelombang mulai pecah (plunging) kemudian gelombang berubah pada fase menggulung (collapsing). Ini terjadi karena perubahan kedalaman air yang simultan dikarenakan box. Pada saat gelombang berada diantara box maka tinggi gelombang berubah menjadi lebih tinggi dibandingkan sebelum gelombang melewati box hal ini menyebabkan kecepatan gelombang setelah melewati box juga lebih cepat.

Pemodelan gelombang dengan SPH memiliki akurasi yang cukup tinggi untuk menangkap fenomena large-deformation surface wave. Ini terlihat juga dari hasil pemodelan dengan menggunakan NWT yang besar [9].

Gambar 5. merupakan grafik perbandingkan elevasi tinggi gelombang large-deformation surface wave $2 \mathrm{D}$ dan 3D. berdasarkan perbandingan hasil nilai elevasi tinggi gelombang terdapat sedikit perbedaan pada hasil 3D. Ini dikarenakan pada domain 3D, partikel lebih kompleks dan bergerak tidak beraturan ke segala arah dibandingkan dengan domain 2D. Berdasarkan hasil tersebut SPH dapat memprediksi efek dari perubahan kedalaman air secara simultan baik dengan analisa 2D maupun 3D. Hasil ini menunjukkan SPH memiliki akurasi cukup tinggi dan SPH sangat dimungkinkan untuk digunakan pada fenomena gelombang yang lebih komplek seperti solitary wave, gelombang tsunami maupun interaksi gelombang dengan struktur (FSI).
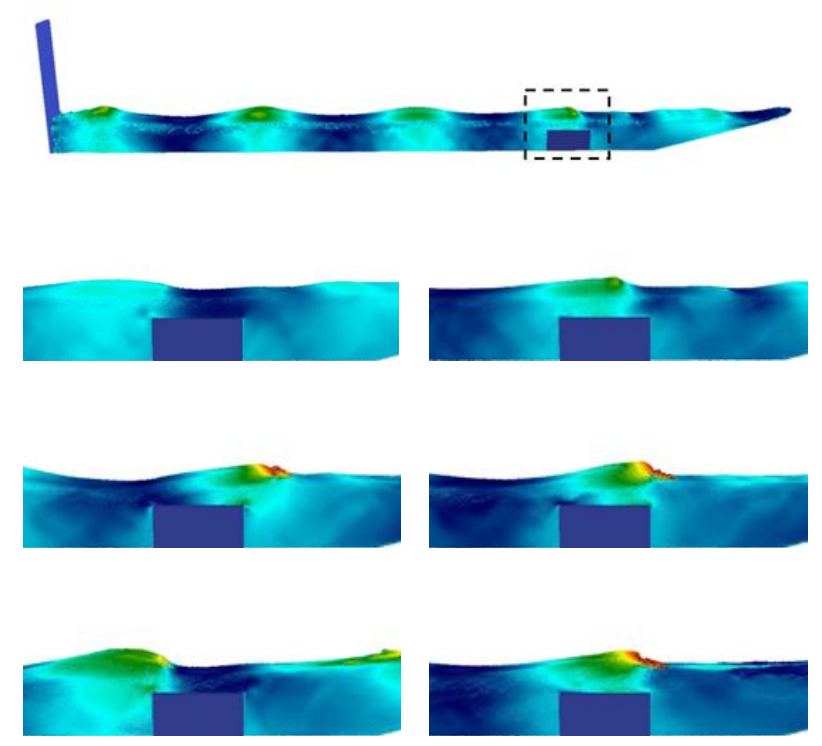

Gambar 4. Snapshot dari large deformation of waves surface pada $\mathrm{t}=16 \mathrm{~s}, 17.5 \mathrm{~s}, 20 \mathrm{~s}, 21 \mathrm{~s}$, $27.5 \mathrm{~s}, 29 \mathrm{~s}$.

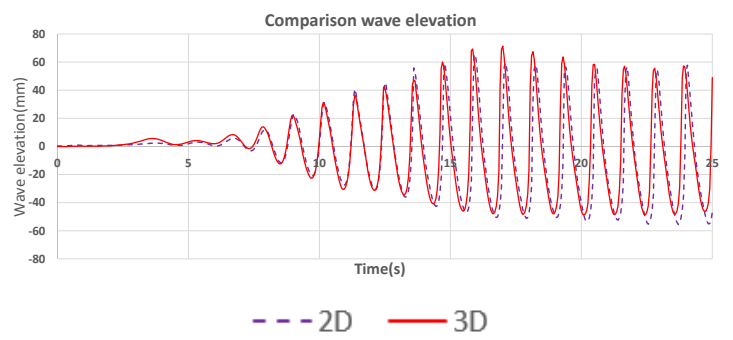

Gambar 5. Perbandingan hasil tinggi elevasi gelombang large-deformation dengan box untuk 2D dan 3D.

\section{KESIMPULAN}

SPH merupakan salah satu metode dinamika fluida komputasi yang cukup baru yang berbasis Lagrangian dan non-grid menunjukkan hasil akurasi yang cukup tinggi untuk pemodelan numerik gelombang. Baik gelombang reguler tanpa adanya perubahan kedalaman air maupun adanya perubahan kedalaman air secara simultan dengan box. SPH dapat memprediksi fenomena "bank effects" karena terjadinya perubahan kedalaman air secara simultan dengan menggunakan obstacle box.

Berdasarkan hasil simulasi numerik SPH elevasi tinggi gelombang dapat tervalidasi dengan hasil eksperimen untuk gelombang reguler. Elevasi gelombang dapat diprediksi dengan akurat oleh SPH baik untuk gelombang reguler maupun untuk gelombang nonlinear dengan menggunakan box untuk mendapatkan efek large-deformation surface wave. 


\section{UCAPAN TERIMA KASIH}

Penulis pertama mengucapan terima kasih kepada kemenristekdikti untuk beasiswa BPP-LN No. 181.47/E4.4/2014.

\section{DAFTAR PUSTAKA}

[1] A. C. Crespo, D. Benedict, J. M. Dominguez, A. Barreiro, and M. Go, "GPUs, a New Tool of Acceleration in CFD : Efficiency and Reliability on Smoothed Particle Hydrodynamics Methods," PLoS One, vol. 6, no. 6, 2011.

[2] J. J. Gingold, Monaghan, "Smoothed Particle Hydrodynamics: Theory and Application to Non-Spherical Stars," Mon.Not.R.ast.Soc, vol. 181, pp. 375-389, 1977.

[3] J. J. Monaghan, "Simulating Free Surface Flows with SPH," J. Comput. Phys., vol. 110, no. 2, pp. 399-406, 1994.

[4] A. Barreiro, A. J. C. Crespo, J. M. Domínguez, and M. Gómez-Gesteira, "Smoothed Particle Hydrodynamics for coastal engineering problems," Comput. Struct., vol. 120, pp. 96-106, 2013.

[5] C. Altomare, A. J. C. Crespo, B. D. Rogers, J. M. Dominguez, X. Gironella, and M. Gómez-Gesteira, "Numerical modelling of armour block sea breakwater with smoothed particle hydrodynamics," Comput. Struct., vol. 130, pp. 34-45, Jan. 2014.

[6] C. Altomare et al., "Long-crested wave generation and absorption for SPH-based DualSPHysics model," Coast. Eng., vol. 127, no. June, pp. 37-54, 2017.

[7] M. Antuono, A. Colagrossi, S. Marrone, and C. Lugni, "Propagation of gravity waves through an SPH scheme with numerical diffusive terms," Comput. Phys. Commun., vol. 182, no. 4, pp. 866-877, 2011.

[8] A. J. C. Crespo et al., "DualSPHysics: Open-source parallel CFD solver based on Smoothed Particle Hydrodynamics (SPH)," Comput. Phys. Commun., vol. 187, pp. 204-216, 2015.

[9] A. Trimulyono, H. Hashimoto, and K. Kawamura, "Experimental Validation of SPH for Wave Generation and Propagation in Large Wave Tank," in Proceedings of the Twenty-seventh (2017) International Ocean and Polar Engineering Conference San Francisco, CA, USA, June 25-30, 2017, pp. 584-590.
[10] G.-R. Liu and M. B. Liu, Smoothed Particle Hydrodynamics: A Meshfree Particle Method. World Scientific, 2003.

[11] H. Wendland, "Piecewise polynomial, positive definite and compactly supported radial functions of minimal degree," $A d v$. Comput. Math., vol. 4, no. 1, pp. 389-396, 1995.

[12] J. J. Monaghan, "Smoothed Particle Hydrodynamics," Annu. Rev. Astron. Astrophys., vol. 30, pp. 543-74, 1992.

[13] D. Molteni and A. Colagrossi, "A simple procedure to improve the pressure evaluation in hydrodynamic context using the SPH," Comput. Phys. Commun., vol. 180, no. 6, pp. 861-872, 2009. 